\title{
Autoplagio y duplicación: un asunto en contra de la ética en la investigación científica
}

\author{
Self-plagiarism and Duplication of Publications: a Matter against \\ Ethics in Scientific Research
}

\section{Autoplágio e duplicação: uma questão contra a ética na pesquisa cientifica}

Entre las malas conductas en investigación científica se encuentran los casos de plagio, autoplagio y duplicación; que atentan contra la veracidad y credibilidad de las publicaciones y revistas científicas que se enfrentan a estos casos. Así, para garantizar que los procesos de evaluación editorial y publicación se realicen adecuadamente y a la luz de los lineamientos éticos, a lo largo de los años se han consolidado asociaciones y comités cuyo objetivo fundamental es asegurar la entrega de productos científicos de calidad; algunos ejemplos de estas organizaciones son: la Asociación Mundial de Editores Médicos (WAME, por sus siglas en inglés), el Comité Internacional de Editores de Revistas Médicas (ICMJE, por sus siglas en inglés) y el Comité de Ética para Publicaciones (COPE, por sus siglas en inglés), entre otros.

En este contexto, la WAME define el plagio como el uso de ideas o palabras publicadas y no publicadas de otros (u otra propiedad intelectual) sin atribución o permiso, y presentarlas como nuevas y originales en lugar de derivadas de una fuente existente; y el autoplagio como la práctica de un autor que utiliza partes de sus escritos previos sobre el mismo tema en otra de sus publicaciones, sin citarlas adecuadamente. Estas conductas atentan contra los derechos de autor asignados al editor (1); situaciones que no solo se manifiestan en relación al texto, sino que pueden encontrarse en imágenes, fotografías y tablas presentadas a un comité editorial aparentemente como originales.

El autoplagio ocurre principalmente en tres situaciones: 1. Publicar el mismo trabajo en lugares distintos con títulos diferentes, 2. Usar, en una nueva obra, material ya publicado, y 3. Para el caso particular de los estudiantes, presentar para evaluación de un curso o programa un trabajo que ha sido presentado previamente, con el fin de cumplir los requisitos del curso o grado(2). Estas acciones en ocasiones se realizan en el contexto del afán investigativo, pero afectan seriamente las actividades de publicación científica, quebrantan la buena fe de un comité editorial y los lectores, además de agotar tiempo y esfuerzo editorial en obras no originales.

De igual forma el ICMJE, en el marco de supervisar y garantizar los lineamientos éticos en materia de publicación científica, cada año expide las Recomendaciones para la realización, información, edición, y publicación de trabajos académicos en las revistas médicas, en donde se abordan las malas conductas descritas, y además, se define la publicación duplicada como el documento que se superpone considerablemente a otro ya publicado, sin referencia clara y visible a la publicación anterior (3), se constituye en un acto poco ético que engaña a la comunidad académica, desconoce legalmente los derechos de autoría que se ha cedido a la revista que lo acepta (4), y claramente contraviene la ética en investigación científica.

Es evidente que este tipo de conductas son cada vez más frecuentes, y entre los factores que las favorecen se pueden mencionar: el fácil acceso a la información; el desconocimiento de la adecuada escritura científica y referenciación; la necesidad de obtener grados académicos, reconocimientos, prestigio investigativo, asistencia a congresos, entre otros; circunstancias que no justifican 
dichas prácticas (5), y ponen en evidencia la falta de formación ética e investigativa desde los niveles inferiores de formación.

Un estudio publicado en el año 2012 en la revista Proceedings of the National Academy of Sciences (PNAS), analizó 2,047 artículos retractados en la base de datos PubMed hasta mayo de 2012, y se identificó que en la mayoría de ellos esta retractación se debió a alguna forma de mala conducta. Entre las razones más comunes se encontraron el fraude o sospecha de fraude en el $43.4 \%$, publicación duplicada en el $14.2 \%$ y plagio en el $9.8 \%$; el resto de artículos fueron tipificados como causas desconocidas o por varios motivos (6). Según el artículo, dicha conducta se presenta en el contexto de la competitividad en la investigación, en donde la cantidad aporta mayores beneficios respecto a la calidad, producto quizás de las exigencias del trabajo científico, lo que se ha denominado "publicar o perecer"(2).

Estudios realizados en países de América Latina demuestran que el problema de fraude se presenta y se inicia desde las aulas. En Colombia, un estudio realizado en la Universidad de Cartagena en el año 2010, en el que se analizó el fraude académico, se encontró que muchos estudiantes, a pesar de que lo identifican como una conducta deshonesta, lo justifican por el logro de una calificación que garantice la aprobación de una asignatura por encima de la adquisición de los conocimientos necesarios (7). Dichas situaciones pueden ser el reflejo de lo que se observa actualmente a nivel investigativo, en una cadena de desconocimiento de los lineamientos éticos y subestimación de los procesos editoriales; sin tener en cuenta que la investigación es una actividad consciente y necesaria, producto de la praxis cotidiana y que se convierte en el vehículo de profundización, creación y difusión de conocimientos, no un hecho fortuito o aislado, con solo un objetivo de requisito preestablecido(5), para obtención de beneficios académicos.

De esta manera, las repercusiones ocasionadas por dichas conductas afectan los procesos editoriales construidos sobre la honestidad y la ética; vulneran la credibilidad de la revista y se pierde la confianza depositada en ella por los lectores. Además, menoscaban los principios éticos que constituyen la columna vertebral de la investigación científica (8). En estos casos, la COPE brinda asesoramiento sobre las pautas a seguir: los autores deben ser objeto de una auditoria editorial, así como el retiro de su publicación, responsabilidad que también recae sobre los coautores y tutores de la publicación(9); sin embargo, la realidad es que las correcciones varían según la percepción personal de los implicados y quedan a libre decisión de comités y académicos. Así, los correctivos se delimitan según el nivel de formación de los autores, subdividiendo las malas conductas cometidas por un alumno que inicia la formación universitaria y el profesional que ya conoce las exigencias de la educación superior y que ha decidido dedicarse a la investigación científica (como un alumno de doctorado o un académico), los cuales deben enfrentar correcciones severas (2); esta laxitud en el abordaje del tema puede estar generando el aumento de malas conductas en estudiantes de pregrado y posgrado cuyo objetivo es obtener un grado o reconocimiento sin el esfuerzo y dedicación requerido.

En tales situaciones la forma de proceder puede variar, porque intervienen la ética y la moral de quien evalúa los textos y el momento en el que haya sido detectado el caso (proceso editorial, evaluación por pares, publicación). En una investigación realizada en 51 investigadores mexicanos de alto nivel, en relación a la percepción de plagio, 50 de los participantes manifestaron haber encontrado plagio en por lo menos una ocasión en los textos en los que fueron evaluadores externos calificados, pero a pesar de ello, a juicio de los propios académicos toman acciones mínimas y no se profundizan en el tema, manifestando que: "simplemente dejo de seguir revisando el texto y lo doy como no entregado" y "creo que ante la primer evidencia de piratería ya no tiene caso seguir leyendo y por supuesto rechazo la publicación porque ya no se puede confiar en el resto", con lo cual se concluye que la falta de acción se deriva de una postura de "no implicarse"(10). Situación a la que se exponen frecuentemente comités editoriales y pares evaluadores, "¿qué hacer cuando las evidencias sugieren plagio o duplicación en un producto científico?, ¿conviene dejar hacer y dejar pasar?, si se detecta a tiempo, ¿basta con no dejar que se publique algo que muestra evidencias de ser plagiado o duplicado? o cuando el trabajo ya se ha publicado, ¿Qué tan pertinente y práctico resulta emprender acciones serias para dar marcha atrás?, ¿Qué consecuencias se vislumbran en esta toma de decisiones?" (10), son algunos de los interrogantes que deben resolver las revistas implicadas.

En segunda instancia, se deben encontrar instituciones encargadas de la vigilancia y control ético de las publicaciones; por ejemplo, en China cuentan con una oficina de integridad en la investigación científica y tiene entre sus funciones dar respuesta integral a la mala conducta en investigación(11). Aunque en Colombia no se cuente con recursos similares, desde el año 2013 el gobierno nacional viene trabajando sobre el tema de la ética en investigación y en el 2017 se consolidó la Política de Ética, Bioética e Integridad Científica, y entre sus metas para el 2022 se espera contar con una instancia nacional que reciba, investigue, controle y realice el seguimiento de las faltas a la integridad científica(12). Por ahora dicha institución seguirá siendo una utopía, y las decisiones, así como correcciones estarán a cargo de los comités editoriales e instituciones implicadas.

De esta forma, y comprometidos con la entrega de productos científicos de calidad, las revistas científicas deben considerar el dejar hacer, sin dejar pasar, con modelos adecuados de prevención de estos casos desde el proceso editorial, con personal entrenado, formatos de evaluación para pares evaluadores que incluyan casillas de malas 
conductas, con el objetivo de que al detectarse se incluyan las evidencias. Además es importante el uso de un software adecuado para identificar el porcentaje de originalidad de un manuscrito, por ejemplo Turnitin ${ }^{\circledR}$, iThenticate ${ }^{\circledR}$ y Viper, entre otros. En relación al porcentaje de originalidad aceptado por una revista, esta varía según las indicaciones adoptadas para sus autores; sin embargo, hace unos años se presentaba como línea de corte un 50\% de novedad, pero en la actualidad la mayoría de revistas solicitan que el material sea inédito en un $80 \%$ (13). Igualmente, sería de gran utilidad crear una red de identificación de estos casos de forma cooperante entre editores, ya que probablemente el autor o autores implicados no volverán a enviar un artículo a la revista en mención, pero sí podrían enviarlo a otras, y continuar atentando contra el desarrollo científico, la ética en investigación y degastar los procesos editoriales.

María Fernanda Barragán Vergel, MD. Universidad Autónoma de Bucaramanga Correo electrónico: mbarragan216@unab.edu.co

\section{Referencias}

1. World Association of Medical Editors. Recommendations on Publication Ethics Policies for Medical Journals [Internet]. 2004 [ 21 sept 2018]. Disponible en: http:// ww.wame.org/about/recommendations-on-publicationethics-policie

2. Montecinos AM. Plagio Y Ética De La Investigación Científica. Rev Chil Derecho [Internet]. 2013; 40(2): 711-26. Disponible en: https://scielo.conicyt.cl/pdf/ rchilder/v40n2/art16.pdf

3. ICMJE. Recommendations for the Conduct, Reporting, Editing, and Publication of Scholarly Work in Medical Journals. Citeseer [Internet]. 2016 [25 sept 2018]. Disponible en: http://citeseerx.ist.psu.edu/viewdoc/ download?doi=10.1.1.408.8144\&rep=rep1\&type=pdf
4. Bannura G. Publicación duplicada y autoplagio en publicaciones médicas. Rev Chil Cir. 2017; 69(1):1-2. Disponible en: http://dx.doi.org/10.1016/j.rchic.2016. 11.009

5. Molina A, Selín M. Plagio en la publicación científica MediSur. 2016; 14(1):12-4.

6. Fang F, Grant-Steen R, Casadevall A. Misconduct accounts for the majority of retracted scientific publications. Proc Natl Acad Sci [Internet]. 2012; 109(42):17028-33. Disponible en: http://www.pnas.org/ cgi/doi/10.1073/pnas.1212247109.

7. Díaz A, Gonzáles F, Carmona L. Relación del fraude académico con situaciones personales que enfrentan los estudiantes en la Facultad de Odontología de la Universidad de Cartagena (Colombia). Salud Uninorte. 2010; 26(1):85-97.

8. Laufer M, Rabinovich J. Originalidad y duplicación en publicaciones científicas. Ecol Austral [Internet]. 2003; 13(2):129-32. Disponible en: http://www.scielo.org.ar/ scielo. php?script=sci_arttext \&pid=S1667-782X 2003000200001

9. Committee on Publication Ethics. About COPE [Internet]. 2018 [20 sept 2018]. Disponible en: https://publicationethics.org/about

10. Hernández M. El plagio académico en la investigación científica Consideraciones desde la óptica del investigador de alto nivel. Perfiles Educ [Internet]. 2016; 153:120-35. Disponible en: http://www.scielo.org.mx/ pdf/peredu/v38n153/0185-2698-peredu-38-15300120.pdf

11. Ana J, Koehlmoos T, Smith R, Yan LL. Research Misconduct in Low- and Middle-Income Countries. PLoS Med. 2013; 10(3):1-6. Disponible en: http:// journals.plos.org/plosmedicine/article?id=10.1371/journ al.pmed.1001315.

12. Dirección de Fomento a la investigación. Política de ética, bioética e integridad científica. Colciencias [Internet]. 2017 [20 sept 2018]. Disponible en: http://www.colciencias.gov.co/sites/default/files/upload/ noticias/politica-de-ctei.pdf

13. Spinak E. Etica editorial y el problema del plagio. Scielo en perpectiva [Internet]. 2013 [20 sept 2018]. Disponible en: http://blog.scielo.org/es/2013/10/02/etica-editorial-yel-problema-del-plagio/ 